\title{
O profissional em educação física no Brasil: Desafios e perspectivas no mundo do trabalho
}

\author{
Marcello Pereira Nunes ${ }^{1}$ \\ Sebastião Josué Votre ${ }^{2}$ \\ Wagner dos Santos ${ }^{3}$ \\ ${ }^{1}$ Centro de Educação, Universidade Federal do Espírito Santo, Vitória, ES, Brasil \\ ${ }^{2}$ Departamento de Educação Física, Universidade Gama Filho, Rio de Janeiro, RJ, Brasil \\ ${ }^{3}$ Centro de Educação Física e Desportos, Universidade Federal do Espírito Santo, Vitória, ES, Brasil
}

Resumo: Neste trabalho articulamos os desafios na formação do profissional bacharel em educação física, nos documentos oficiais e a sua intervenção no mundo do trabalho. Ampliamos as percepções e avaliamos a proposta de formação nos saberes e conhecimentos para esse campo de atuação; por fim levantamos desafios e perspectivas para formar o bacharel em educação física no Brasil. A análise de conteúdo dos documentos oficiais sobre a formação do bacharel oferece suporte para nossas proposições concernentes à formação desse profissional, tendo como referencial teórico estudos do campo da educação e artigos específicos da área. Com base nos resultados dessa análise, construímos uma matriz dos saberes estabelecidos nos documentos oficiais. Elaboramos um conjunto de propostas desafiadoras para a formação desse profissional, recontextualizada e articulada com os interesses das comunidades a que esse profissional se propõe servir.

Palavras-chave: formação profissional; bacharel em educação física; currículo; Diretrizes Curriculares Nacionais.

The physical education profession in Brazil:

Challenges and perspectives in the marketplace

\begin{abstract}
In this paper we discussed the challenges during training for the physical education profession, the official documents requirements, and the physical education insert in the marketplace. We expand our perceptions in the area, and evaluate the purpose of knowledge and expertise achieved in this field; finally, we predict challenges and perspectives to the bachelor's professional preparation in physical education in Brazil. The content analysis of official documents about the bachelor's education supports our propositions concerning the background in this profession, by introducing theoretical studies in the field of education and specific articles in the area. Based on the results of this analysis, we constructed a matrix of knowledge established from the official documents. We developed a set of challenging proposals for professional training, and adapted and articulated them based on varied communities's interests for which this professional is trained to serve.
\end{abstract}

Keywords: professional training; bachelor of physical education; curriculum; National Curriculum Guidelines.

\section{Introdução}

Este estudo tem o propósito de contribuir com análises e proposições para a formação do profissional de educação física no Brasil em suas articulações no mundo do trabalho, que oferecem oportunidades de ocupação temporária e permanente para o profissional de educação física. Nosso interesse específico é analisar e avaliar as propostas oficiais de formação do bacharel e os projetos pedagógicos dos cursos de educação física em seu formato prescrito e regulamentado. Para Sacristán (1999), o currículo prescrito e regulamentado é aquele que se processa no âmbito das decisões políticas e administrativas.

Nesta década de 2010, no Brasil, estamos diante de um cenário de reformas e de reorganização no campo das políticas educacionais. O objetivo de tais reformas e reorganizações é buscar a melhoria da qualidade da educação brasileira nos diversos níveis de ensino. Nesse sentido um modelo de avaliação do sistema educacional vem sendo construído desde a década de 1990 .

Os órgãos governamentais que gerenciam a educação no ensino superior, em interlocução 
com os resultados de levantamentos sociodiagnósticos da realidade educacional de cada campo, implementam mudanças e, via resoluções, instituem novas orientações com o intuito de aperfeiçoar as proposições conceituais e os elementos didático-pedagógicos da intervenção profissional em educação física em seus diferentes contextos.

O Conselho Nacional de Educação transfere para os profissionais de cada área de conhecimentos a competência de deliberar sobre as diretrizes curriculares, para os cursos de graduação. Essas diretrizes curriculares, no entender do Conselho, constituem parâmetros balizadores para a elaboração dos projetos de cursos e dos currículos de formação acadêmicoprofissional das instituições de ensino superior.

Da análise das diretrizes infere-se que os currículos dos cursos superiores caracterizam-se por excessiva rigidez que advém, em parte, da fixação detalhada de mínimos curriculares e da progressiva diminuição da margem de liberdade que fora concedida às instituições para organizarem suas atividades de ensino. Os relatores do Conselho confirmam uma semelhança formal entre os cursos de graduação no Brasil e uma tradição curricular burocrática que emperra o desenvolvimento do graduando frente às palpitações do mercado. $A$ isso se acrescenta uma excessiva carga de disciplinas obrigatórias e o prolongamento do tempo de formação. Os relatores concordam também em que, em parte, tais práticas estão em contradição com a Lei de Diretrizes e Bases da Educação Nacional, que assegura maior flexibilidade para as instituições na organização de seus cursos e considera a graduação como uma etapa inicial da formação continuada.

Os pareceres obedecem às orientações do Ministério da Educação que, em 2001, propõe as Diretrizes Curriculares Nacionais para a Formação de Professores da Educação Básica, independentemente dos debates da comunidade da educação física sobre a licenciatura ampliada e o bacharelado. O Ministério da Educação partilha a "[...] concepção de professor como profissional do ensino que tem como principal tarefa cuidar da aprendizagem dos alunos, respeitada a sua diversidade pessoal, social e cultural" (BRASIL, 2001, p. 6).

A licenciatura ganha terminalidade e integralidade própria em relação ao bacharelado, constituindo-se em projeto de curso específico. $\mathrm{O}$ motivo dessa mudança é porque os cursos de licenciatura funcionavam como anexos dos cursos de bacharelado, o que impedia a construção da identidade teórica, epistemológica e profissional do professor. Os projetos de cursos da licenciatura, anteriores à Resolução 01/02 que definiu as orientações para formar o professor do ensino básico, tinham seus currículos com ênfase nos conteúdos específicos da área de conhecimento disciplinar. A licenciatura, nesta proposta, construía sua identidade centrada na formação e na atuação do físico, do historiador, do biólogo, entre outros, para atuarem como docentes.

$\mathrm{Na}$ Resolução 01/02, a matriz curricular da formação do professor, seja qual a área de conhecimento, apresenta e detalha as competências relativas à compreensão do papel social da escola, à operacionalização do conhecimento pedagógico que favoreça 0 aperfeiçoamento da prática pedagógica do profissional que atua na educação formal, desde a educação infantil até o ensino médio (BRASIL, 2002).

Para o bacharelado, as Diretrizes Curriculares Nacionais (Res. n. 07/04) tem a orientação para a construção de uma formação específica para cada área do conhecimento, com definição de perfis profissionais e carreiras, privilegiando as competências intelectuais que atendam às demandas sociais do mundo do trabalho (BRASIL, 2004).

A legislação para a formação do bacharel sugere conferir maior autonomia às instituições educacionais superiores na definição dos currículos de seus cursos, a partir da explicitação das competências e das habilidades que se deseja desenvolver, através da organização de um modelo pedagógico capaz de entender e debater a dinâmica das demandas da sociedade. Após definidos os marcos para construção da identidade do bacharel como profissional em educação física, as comissões de especialistas das diferentes áreas e campos do saber construíram diretrizes curriculares específicas.

A Comissão de Especialistas em Educação Física elaborou as diretrizes para a área, em que reconheceu um novo cenário para a criação dos cursos e as identidades distintas a) para a atuação do professor de educação física, na 
educação básica e b) para o bacharel, no mundo do trabalho não escolar.

Segundo as diretrizes, o bacharel atua no campo de trabalho não escolar, em espaços como clubes, academias, áreas de lazer, iniciação esportiva e atividades físicas fora da grade curricular escolar, empreendimentos físicoesportivos, bem como em secretarias de esporte e lazer das redes municipal e estadual, em projetos sociais, associações esportivas e recreativas, centros de reabilitação física e de educação para pessoas com deficiência, em órgãos públicos e de iniciativa privada nos setores de administração, organização esportiva, recreativa e de lazer, em esportes marítimos e atividades físico-esportivos de praia, em prestação de serviço em condomínios, empresas e hospitais, em consultorias, projetos e eventos de esportes de aventura e ligados à natureza.

Além desses mercados consolidados pela educação física, vislumbramos também possibilidades de campos de atuações em áreas emergentes: esportes marítimos e atividades físicas -- esportivas de praia, prestação de serviço em condomínios, empresas e hospitais, consultorias, projetos e eventos, equipes multiprofissionais.

Em síntese, o bacharel em educação física é um profissional capaz de intervir acadêmica e profissionalmente nos campos da prevenção, promoção, proteção e reabilitação da saúde, na educação, projetos sociais, esportes, lazer e gestão de empreendimentos dessa área. A listagem é exaustiva, pois há espaço para o bacharel em todas as circunstâncias, em que se configuram atividades físico-esportivas fora da escola.

Algumas questões emergem nesse novo cenário de formação profissional com a entrada dos cursos de bacharelado em educação física. Qual é a contribuição dos documentos oficiais? Como se manifestam a rejeição e a resistência às orientações prescritivas? Além da escola, para quais áreas estamos formando profissionais em educação física? Qual é o grau de adequação na formação do bacharel para atuar nos megaeventos esportivos? Qual é o grau de adequação do projeto de bacharelado dos documentos oficiais face às necessidades do mundo do trabalho? Qual a configuração do projeto, em termos de terminalidade $e$ integralidade? As instituições brasileiras de ensino superior estão com dificuldades em responder às perguntas acima e em organizar os conhecimentos específicos do bacharel em educação física.

O objetivo deste estudo foi explorar os documentos oficiais e a literatura pertinente sobre formação profissional, com vistas a articular inferências e propor sugestões para o bacharel em educação física no Brasil.

\section{Método}

Este estudo tem como método a análise de conteúdo, que procura "[...] descrever e interpretar opiniões, estereótipos, representações, mecanismos de influências, evoluções individuais e sociais" (BARDIN, 2009, p. 7).

Elaboramos procedimentos de análise comparativa qualitativa para inferir sobre os documentos oficiais, com foco nos artigos que tratam do conhecimento específico e ampliado, das competências educacionais e das orientações de natureza ética e moral do bacharel em educação física.

Entendemos nesse estudo a formação profissional em educação física, assim como outras áreas de intervenção, um espaço de lutas e interesses epistemológicos, educacionais, políticos e culturais, onde as relações de poder circunscritas no campo científico dessa profissão se materializam em contextos curriculares elaborados na história constitutiva da formação profissional em educação física.

Para analisar esses materiais produzidos historicamente nos embasamos nos estudos de Bloch (2001) e Ginzburg (2002), e no cruzamento das fontes que estão no texto e fora dele. Os documentos enquanto fontes precisam ser questionadas, produzindo um novo texto. Questionamos as fontes sobre os modos de sua produção, do grupo que as construíram, das impressões e das relações desse grupo inscritas nos textos e nas formas. Vasculhando a história constitutiva e seus contextos curriculares de formação profissional da educação física no Brasil.

Ao analisar esse novo cenário, nossa intenção é "[...] ir muito além de revelar uma contradição ideológica, mas ir precisamente ao coração do modo de funcionamento e organização de uma atividade social complexa", nos termos de Becker (2007, p. 195). 
Elaboramos categorias temáticas de análise, com 0 intuito de identificar perspectivas qualitativas para a recontextualização do mundo do trabalho da educação física brasileira. As categorias de análise são: a) formação profissional e mundo do trabalho; b) saberes e competências; c) ações empreendedoras e inovadoras; d) aspecto acadêmico e instrumental.

Utilizamos essa técnica de categorização, para compreender, interpretar e compreender os documentos oficiais da formação profissional em educação física e organizar um quadro descritivo do real. $\mathrm{Na}$ construção e revisão do quadro teórico identificamos produção relativamente diminuta, no conjunto de estudos anteriores sobre o tema do bacharelado em educação física. Nesse sentido, é oportuno e relevante o desenvolvimento de projetos de pesquisas que contribuam com esse tema.

Já para o licenciado, o material acadêmico disponível é abundante e relevante. A literatura educacional contribui com análises na perspectiva da formação do professor, do currículo e dos projetos de políticas públicas, em seus diversos sentidos.

\section{Os desafios do bacharel em educação física no Brasil}

Para o licenciado, está legitimado historicamente um lugar específico, diferente de outros lugares sociais, onde os conhecimentos chamados escolares se "socializam". Os métodos pedagógicos estabelecem um modo escolar de articulação dos saberes e conhecimentos, acumulados, objetivados e codificados socialmente.

A escola é o espaço específico para articulação e permanência desses saberes objetivados. A pedagogização das relações sociais e de aprendizagens se configura nos saberes formalizados, delimitados e codificados, tanto na composição de seus conteúdos escolares quanto na forma de ensinar. De alguma maneira, o modo de intervir na escola se impôs a outros modos de socialização dos saberes, tornando-se legítimo e dominante.

O licenciado, responsável por intercambiar esses saberes no espaço da escola, tem em sua formação inicial um conjunto de princípios, fundamentos e procedimentos legitimados que se aplicam às diferentes etapas e modalidades de ensino. $^{1}$ O modo escolar de intervenção incorporado pelos professores se organiza em um espaço e tempo específico, cujo acesso não é permitido aos olhares "não pedagógicos", dos profissionais bacharéis. Os bacharéis em educação física frequentemente atuam como técnicos, treinadores, gestores e empreendedores entre outros, e são profissionais que também ensinam, mas com outro modo de intervenção. Esse é o grande desafio da formação do bacharel em educação física no Brasil. Há uma necessidade de construir e recontextualizar a matriz de conhecimentos específicos desse campo de atuação.

Sem autonomia teórica e metodológica, os formadores do bacharel importam e adaptam o modelo da licenciatura. Entretanto, é um equívoco pensar que se trata de transposição ou de adaptação de uma área para outra. Pois o modo de intervir distingue as carreiras. Assim, o modo de intervir escolar é predominantemente encontrado nos currículos de formação dos bacharéis em educação física, nos conteúdos disciplinares, nas orientações éticas e morais, nos conhecimentos articulados e nas metodologias de ensino.

Como exemplo na licenciatura, o conteúdo de formação profissional em educação física, denominado "Esporte Coletivo-Futebol", tem um modo de intervenção pedagógica que contribui para a construção da corporeidade cultural e para a autonomia dos alunos em relação à prática e aos benefícios e limitações dessas atividades físico-esportivas. O licenciado está sendo formado para intervir no "fazer-saber".

Já na formação do bacharel em educação física, esse mesmo conteúdo, tem orientação para planejar, ensinar de uma ótica que não seja a da escola, coordenar e avaliar essa prática na perspectiva da promoção, proteção e reabilitação da saúde, da educação e reeducação motora, do rendimento físico-esportivo, do lazer e da gestão de empreendimentos relacionados a esta atividade profissional. O bacharel está sendo formado para intervir no "saber-fazer".

Neste contexto específico, licenciado e bacharel em educação física ensinam, mas de modos diferentes e em espaços e tempos diferentes. A formação do bacharel em educação física, nesse novo cenário, permanece marginal,

\footnotetext{
${ }^{1}$ Ver texto de Fuzii, Souza Neto e Benites (2009).
} 
pois não se construiu um conjunto de princípios e conhecimentos que fossem diferentes do modo escolar de intervenção. A legislação em algum sentido avançou, mas as pesquisas e publicações ainda devem articular um conjunto de práticas que possam indicar outros modos de socialização de conhecimentos no campo da educação física e esportes no Brasil.

A formação específica em cada área do conhecimento como propõem as Diretrizes Curriculares Nacionais (CNE/CP, Res. no 01/02, BRASIL, 2002; CNE/CES, Res. № 07/04, BRASIL, 2004), com definições de perfis profissionais e carreiras, privilegiando as competências intelectuais que atendam às demandas sociais do mundo do trabalho, é uma proposta prescritiva.

Neste sentido o tecido articulador para o bacharelado da educação física está em transformar essas propostas normativas em conhecimento específico desse campo do trabalho não escolar, pois este profissional deve ser capaz de intervir acadêmica e profissionalmente nos campos da prevenção, promoção, proteção e reabilitação da saúde, na educação, em projetos sociais, em esportes, lazer e gestão de empreendimentos.

O Ministério da Educação editou as referências curriculares nacionais para os cursos de bacharelado, em maio de 2010 , os quais, em determinado campo do saber, conferem competências ao futuro profissional.

O conceito de competências, no contexto atual, assume novos significados e amplia sua definição para um conjunto de conhecimentos, habilidades, e atitudes, capacitando o ser humano a desempenhar com qualidade sua vida em sociedade. A rede de conhecimentos em que se insere o indivíduo interfere na eficiência da comunicação e na construção de competências.

O conceito de competência se universaliza na medida em que apóia a modalidade de trabalho estruturado, exigindo domínio de conhecimentos científicos e tecnológicos, articulados a desenvolvimento cognitivo, afetivo e social. $O$ bacharel em educação física deve ter as competências básicas para agir de modo reflexivo, apoiado em um conjunto articulado e dinâmico de conhecimentos.

Ser competente, diante de uma situação problema, traduz-se por mobilizar recursos e comportamentos disponíveis, que deverão ser articulados aos pontos críticos identificados na situação, para que seja possível tomar decisões e fazer encaminhamentos pertinentes, adequados ao enfrentamento da situação.

Os projetos dos cursos de educação física no Brasil devem articular competências em seus processos de ensino e aprendizagem, construindo e debatendo as inúmeras situações concretas, articuladas durante a formação de seus profissionais. É criticamente relevante que esses futuros profissionais tenham tempo de viver suas experiências e possam identificar quais são as competências e habilidades que poderão mobilizar para a resolução daquela tarefa ou situação, de forma autônoma.

A identificação desses conhecimentos pertinentes pode ser mediada durante a formação profissional, mas precisamos propiciar uma postura ativa e eficaz diante dos desafios ou problemas. Decidir sobre essa concepção significa romper com ênfases curriculares centradas na simples transmissão de conteúdos, organizados na forma de disciplinas desarticuladas.

As Instituições do Ensino Superior devem sistematizar e planejar seus projetos com metas que fundamentam uma recontextualização aos modelos curriculares de formação do profissional bacharel em educação física.

\section{As perspectivas da formação do bacharel em educação física no Brasil}

Segundo a Comissão de Especialistas da Educação Física, a área de educação física considera formação do bacharel como especialista, enquanto em outros cursos a formação do bacharel é considerada como generalista.

Cada Instituição de Ensino Superior no Brasil articulou seu curso de bacharel em educação física, na perspectiva de apropriação, por parte do graduando, dos conhecimentos conceituais, procedimentais e atitudinais, específicos dos seus modos de intervenção. Esses modos de intervenção devem estar eticamente balizados nos campos da prevenção, promoção, proteção e reabilitação da saúde, da formação cultural, da educação e reeducação motora, do rendimento físico-esportivo, do lazer, da gestão de empreendimentos relacionados às atividades físicas, recreativas e esportivas, além de outros campos que oportunizem ou venham a 
oportunizar a prática de atividades físicas, recreativas e esportivas.

Neste contexto dos alvos de intervenção propomos ações e perspectivas para a formação do bacharel em educação física, em que os projetos de curso devem:

1. Contribuir para a formação inicial de profissionais em educação física capazes de intervir em diferentes contextos, pautados na ética, na competência técnica, oportunizando uma formação permanente, crítica e reflexiva, no âmbito da qualidade de vida, no esporte, na recreação e no lazer;

2. Formar educadores profissionais críticos, com intenção educativa, que percebam a articulação dos conhecimentos com as dimensões política, sociocultural e socioeconômica;

3. Promover aprofundamento de estudos nas diversas áreas de intervenção, conforme o interesse dos graduandos para com o seu projeto de formação acadêmica;

4. Fomentar a produção científica na educação física, esporte e lazer, nas dimensões do ensino, da pesquisa e da extensão;

5. Integrar as várias disciplinas do curso, de forma empreendedora, tratando o conhecimento indissociável da prática, visando superar a intervenção fragmentada e parcial do profissional.

Cabe, ainda, aos projetos de formação do bacharel em educação física, assegurar a prática como componente curricular, o estágio profissional curricular e as atividades complementares.

As propostas e o reordenamento estabelecidos na legislação oficial exigem transformações em hábitos, costumes e crenças dos agentes envolvidos nesse processo. As ideias se coadunam com Goodson (2008) e se aproximam da postulação de Bernstein (1996), segundo a qual o discurso pedagógico constitui códigos de reprodução e manutenção da tradição como verdades únicas.

As Diretrizes Curriculares, em sua configuração normativa, procuraram elaborar mecanismos efetivos, para que as instituições educacionais abandonassem as características de formação profissional por meio da transmissão de conhecimento e informações, e se preparassem para enfrentar os desafios das rápidas transformações da sociedade, do mundo do trabalho e das condições de exercício profissional.

A legislação, em algum sentido, avançou; mas as pesquisas e publicações ainda devem articular um conjunto de conhecimentos e práticas que possam indicar outros modos de socialização e de intervenção do profissional bacharel em educação física e esportes no Brasil.

Propomos que as dimensões de conhecimentos específicos e ampliados que podem compor os programas de disciplinas dos cursos de bacharelado em educação física tenham como referências as seguintes orientações:

a) Dimensões sócio-antropológicas do movimento humano: conhecimentos filosóficos, antropológicos, sociológicos e históricos que enfocam aspectos éticos, culturais, estéticos e epistemológicos inerentes á área;

b) Pedagogia do movimento humano: conhecimentos dos princípios gerais e específicos de gestão e organização das diversas possibilidades de intervenção do profissional no mundo do trabalho, articulados ao processo de ensinoaprendizagem em espaços não escolares;

c) Dimensões ética e científico-tecnológicas do movimento humano: conhecimentos sobre técnicas de estudo e pesquisa e novas tecnologias e seus procedimentos aplicados aos processos de intervenção profissional;

d) Manifestações da cultura do movimento humano: conhecimentos das diferentes manifestações e expressões da cultura do movimento humano na forma de jogos, esportes, ginásticas, danças, lazer, exercício físico/atividade física, rendimento físico-esportivo, avaliação e prescrição de exercício, lutas/artes marciais, prevenção, promoção, proteção e reabilitação da saúde;

e) Dimensões biodinâmicas do movimento humano: conhecimentos sobre 0 ser humano nos aspectos morfológicos, fisiológicos e biomecânicos e dos processos de desenvolvimento humano, contemplando aspectos motores, habilidades e fatores psicológicos da área.

Os cursos formadores e seus docentes precisam acompanhar as transformações acadêmico-científicas da área e de áreas afins, mediante a análise e produção crítica de literatura especializada e do uso de recursos da tecnologia da informação e da comunicação. 
Precisamos criar instrumentos de desenvolvimento profissional contínuo, para formação continuada, adotando atitude de flexibilidade e disponibilidade para mudanças, inovações e empreendedorismo.

\section{O "saber-fazer" do bacharel em educação física e a sua formação profissional}

Silva (2000) assevera que, de alguma forma, as teorias pedagógicas e educacionais são também teorias sobre o currículo. Neste sentido ao abordarmos os processos formativos do futuro profissional, teremos de analisar as teorias de currículo.

A diversidade conceitual na formação do profissional em educação física tem no campo epistemológico, relações de poder, resistência e ideologia, travadas entre as teorias tradicionais, críticas e pós-críticas. Como discurso e linguagem, o currículo possui significados em construção permanente e aberto, onde em um mesmo contexto, podem existir vários discursos constituintes de verdades desses significados, dependendo do emissor.

Para Moreira (1995), os fatores institucionais incorporados nos currículos de formação são influenciados por três fatores: a) o papel exercido pelas lideranças de uma determinada Instituição. Essas lideranças orientam professores segundo suas concepções e tendem a constituir padrão de estabilidade curricular; b) o grau de influência da maior ou menor autonomia da Instituição frente aos mecanismos oficiais de controle curricular; c) o papel relevante de influência na formação profissional dos professores da equipe. Se a formação tender a especialização, as tradições acadêmicas podem ser fortalecidas nesse sentido e vice-versa.

Compreender os conceitos contidos nas Diretrizes Curriculares para o bacharelado em educação física implica conviver com um ritual de afirmação de boas intenções e de ocultamento dos contextos em que vivem os agentes envolvidos nesse tipo de formação profissional. Segundo o discurso prescritivo legal, recortam-se desejos acadêmicos, que pressionam a realidade vivida, e articulam propostas que, na prática, mudam pouco. Para Sacristán e Gómez (1998, p. 137), "[...] se a prática dependesse das propostas que se fazem, seria muito fácil melhorá-la e mudá-la; a história não confirma, precisamente, essa tese". Desenvolver reformas curriculares é pretender que essa inovação possa proporcionar uma mudança, estimular novas contradições e provocar movimentos, que alterem o equilíbrio no contexto dessa formação profissional.

Quadro 1. Comparação das dimensões do conhecimento entre licenciado e bacharel

\begin{tabular}{|c|c|}
\hline Professor licenciado do ensino básico & Profissional bacharel de educação física \\
\hline Dimensões do conhecimento & $\begin{array}{l}\text { Dimensões do conhecimento } \\
\text { Conhecimentos identificadores da área }\end{array}$ \\
\hline \multirow{6}{*}{$\begin{array}{l}\text { I - Conhecimento da cultura geral e profissional. } \\
\text { II - Conhecimento sobre crianças, adolescentes, } \\
\text { jovens e adultos, ncluídas as especificidades dos } \\
\text { alunos com necessidades educacionais especiais e as } \\
\text { das comunidades indígenas. } \\
\text { III - Conhecimento sobre dimensão cultural, social, } \\
\text { políticas e econômica da Educação. } \\
\text { IV - Conteúdos das áreas de conhecimento que serão } \\
\text { objetos de ensino (dimensões biológicas, sociais, } \\
\text { culturais, didático-pedagógicos, técnico-instrumentais } \\
\text { do movimento humano). } \\
\text { V - Conhecimento pedagógico. } \\
\text { VI - Conhecimento advindo da experiência. }\end{array}$} & Formação ampliada \\
\hline & $\begin{array}{l}\text { - Relação ser humano-sociedade } \\
\text { - Biologia do corpo humano } \\
\text { - Produção do conhecimento científico e tecnológico }\end{array}$ \\
\hline & Formação específica \\
\hline & $\begin{array}{l}\text { - Culturais do movimento humano } \\
\text { - Técnico-instrumental } \\
\text { - Didático-pedagógica }\end{array}$ \\
\hline & Conhecimento identificador de aprofundamento \\
\hline & $\begin{array}{l}\text { - Promoção da saúde } \\
\text { - Lazer e aventura } \\
\text { - Rendimento esportivo } \\
\text { - Gestão e empreendimentos } \\
\text { - Projetos sociais } \\
\text { - Outros }\end{array}$ \\
\hline
\end{tabular}


Na formação do bacharel, os projetos de curso devem articular as unidades de conhecimento, na perspectiva da formação ampliada e específica. Para analisar essas dimensões de conhecimentos $^{2}$ elaboramos um quadro comparativo entre o licenciado e o bacharel, com os indicadores: a) formação profissional e mundo do trabalho; b) saberes e competências; c) ações empreendedoras e inovadoras; d) aspecto acadêmico e instrumental.

\section{Resultados e discussão}

A formação profissional e mundo do trabalho: ações empreendedoras e inovadoras

Segundo o Conselho Nacional de Educação na Res. $n^{\circ} 07 / 04$, "caberá à IES articular as unidades de conhecimentos de formação específica e ampliada". Se as IES têm autonomia para criação e elaboração dessas "disciplinas", como diferenciar o que é ampliado e específico na formação profissional? Existe uma abertura para articular esses conhecimentos na formação inicial, porém, a ideia brasileira de investir em um sistema de avaliação nacional, regula a saída dos profissionais, controla e ajusta os conhecimentos ditos "básicos e verdadeiros", elaborados por nossos "guardiões da tradição" (BRASIL, 2004).

Entretanto, as instituições não terão essa competência garantida na prestação de contas na avaliação de desempenho nacional. Pois os projetos pedagógicos devem estar efetivamente pautados nos conhecimentos abordados pelo sistema de avaliação nacional, que não respeita a autonomia e a regionalidade dos projetos (SANTOS, 2010).

As instituições de ensino superior têm asseguradas, por lei, ampla liberdade e autonomia na especificação das unidades de estudos a serem ministradas em seus currículos de formação acadêmico-profissional, permitindo variados tipos de habilitações e um currículo pleno organizado por campos de conhecimentos.

Neste sentido, as Diretrizes Curriculares Nacionais, devem induzir à criação de diferentes formações e habilitações para cada área do conhecimento, possibilitando ainda definir múltiplos perfis profissionais, garantindo maior diversidade de carreiras, promovendo a integração do ensino de graduação com a pós-

${ }^{2}$ (BRASIL. CNE/CP, Resolução. no 01/02, 2002; BRASIL. CNE/CES, Resolução. no-07/04, 2004) graduação, privilegiando, no perfil de seus formandos, as competências intelectuais que reflitam a heterogeneidade das demandas sociais.

Deste modo, as Diretrizes Curriculares Nacionais sugerem conferir maior autonomia às IES na definição dos currículos de seus cursos, a partir da explicitação das competências e das habilidades que se deseja desenvolver, por meio da organização de um modelo pedagógico capaz de adaptar-se à dinâmica das demandas da sociedade, em que a graduação passa a constituir-se numa etapa de formação inicial no processo da educação permanente.

Porém, temos um novo cenário: o antigo licenciado com formação ampliada foi substituído pelo professor da educação básica com licença em educação física ou pelo bacharel em educação física com graduação plena e generalista.

Neste novo contexto de exigências, os programas de pós-graduação em educação física e os agentes envolvidos (especialistas, diretores, coordenadores, docentes, discentes) buscam, timidamente, equacionar os problemas e apontar alternativas de solução. Para Schön (2000), "[...] o que mais precisamos, é ensinar os estudantes a tomarem decisões sob condições de incerteza, mas isso é justamente o que não sabemos fazer" (p. 20).

Faz-se necessário um aprofundamento dos temas relacionados aos projetos de curso e seus currículos de formação, prescrito e regulamentado, bem como das suas metodologias e suas práticas pedagógicas, sua organização de códigos e discursos de apropriação e resistência, suas práticas de controles internos e externos, seus métodos de avaliação e seus conteúdos disciplinares e a sua construção do conhecimento e de saberes.

Portanto, estudar, caracterizar e analisar criticamente esses processos de formação profissional no contexto das IES pode nos fornecer importantes informações na gestão do conhecimento formador para atuação no campo não escolar. Os campos de trabalho específicos e permanentes gerados dessa demanda não estão sofrendo influências da formação do bacharel em educação física Brasileira. Os agentes formadores (especialistas da área, diretores, coordenadores, docentes, discentes), estão sob a 
influência da tradição e resistência, tendo dificuldades na construção de identidades e subjetividades em contextos complexos e instáveis, estabelecidas na formação do bacharel em educação física.

\section{Saberes e competências:}

\section{aspectos acadêmicos e instrumentais}

As Diretrizes Nacionais da Educação Física para o bacharelado em educação física estabelecem a identidade da área, desde que não interfiram na formação do professor para o ensino básico (BRASIL, 2004, art. nำ4). Portanto, quais são os conhecimentos produzidos especificamente na educação física que se articulam com esse novo cenário? Por exemplo, no caso de um profissional de educação física (bacharel), que exerce seu ofício em um projeto social que tem seu foco de intervenção na praça da comunidade, ele terá de adaptar modos de intervenção e metodologias utilizadas na educação escolar? Quais são os conhecimentos que, articulados, formam o objeto de estudo e aplicação acadêmico-profissional das diferentes manifestações e expressões do movimento humano? Qual seria o "novo" tecido articulador de conhecimentos denominado por essa resolução como ampliado e específico na formação desse profissional? Se os cursos são diferentes, como justificar que os professores das IES que ministram aulas de disciplinas do curso de professores do ensino básico, também ministram aulas no bacharelado em educação física?

As Diretrizes Curriculares do Professor da Educação Básica estabelecem os conteúdos das áreas de conhecimentos específicos que serão objetos de ensino desse componente curricular em educação física. No art. 8 das Diretrizes Curriculares do Bacharelado em Educação Física ficam estipuladas as dimensões biológicas, sociais, culturais, didático-pedagógicas, técnicoinstrumentais do movimento humano, como sendo esses conhecimentos específicos. Como conhecimentos específicos de uma área de intervenção não curricular (em contextos não escolares), podem dar conta de intervenções curriculares (em contextos da escola)? Não podemos resolver este problema com transposição didática, e sim construindo um novo tecido articulador de conhecimentos. Precisamos definir as competências e saberes para cada tipo de formação.

\section{Considerações finais}

Precisamos elaborar um "novo" tecido articulador de conhecimentos denominados como ampliado e específico na formação desse profissional. Se os cursos são diferentes (licenciatura e bacharelado), como justificar ementas, bibliografias e programas de disciplinas iguais aos cursos?

Com relação aos estágios profissionais curriculares, se faz necessário um esforço na formulação da nova área da educação física, para que possamos consolidar as competências exigidas para 0 exercício da acadêmicoprofissional, previstos na legislação. Conforme já mostramos, no âmbito da formação do professor do ensino básico, é possível verificar produção acadêmica e experiências positivas com relação a esse tema.

É relevante destacar a importância das condições do contexto em que os agentes envolvidos se configuram, e como projetam e compartilham suas utopias, ideologias, valores éticos e ideais diversos. Teremos de discutir também o conceito de disciplina e de área de conhecimento no sentido macro e micro da formação do profissional de educação física.

As propostas e o reordenamento estabelecidos na legislação oficial exigem transformações em hábitos, costumes e crenças dos agentes envolvidos nesse processo. Esse é o grande desafio, que precisamos enfrentar. Elaborar e implementar reformas curriculares implica que essa inovação possa proporcionar mudanças, estimular novas contradições e provocar movimentos, que alterem o equilíbrio no contexto dessa formação profissional. Caso contrário, teremos um ritual de afirmação de boas intenções e de ocultamento dos contextos em que vivem os agentes envolvidos nesse tipo de formação profissional. $O$ nosso desafio está em recontextualizar os modos e os conteúdos da formação profissional do bacharel em educação física.

São comuns as denúncias de que os conteúdos propagados no currículo são caricaturas desses conhecimentos. De forma geral, é necessário analisar a opção de formação, pautada na distribuição dos conteúdos de ensino em disciplinas ou em áreas de conhecimentos separados. Percebemos que, durante a formação, não há aprendizagem de tudo, e nem todos 
aprendem da mesma forma e, portanto, dificultase o caminho a trilhar.

É necessário, nesse momento, recontextualizar a formação do profissional de educação física, construindo e elaborando modos não escolares para planejar, prescrever, ensinar, orientar, assessorar, supervisionar, controlar e avaliar projetos e programas de exercícios físicos/atividades físicas, esportivas e de lazer, para intervir na sociedade.

Não encontraremos respostas simples e universais, na tentativa de racionalização das idéias orientadoras das Diretrizes Curriculares para os Cursos de Educação Física, porém cabenos mostrar como é possível o diálogo entre o prescrito e o cotidiano dessa formação profissional. As ideias e as práticas ganham sentido no contexto real da formação, a partir das múltiplas transformações do cotidiano.

\section{Referências}

BARDIN, L. Análise de conteúdo. Lisboa: Edições 70, 2009.

BECKER, H. S. Segredos e truques da pesquisa. Rio de Janeiro: Jorge Zahar, 2007.

BERNSTEIN, B. A estruturação do discurso pedagógico: classes, códigos e controles. Petrópolis: Vozes, 1996.

BLOCH, M. L. B. A apologia da história: o ofício do historiador. Rio de Janeiro: Jorge Zahar, 2001.

BRASIL. Ministério da Educação. Conselho Nacional de Educação. Parecer no 009/2001, de 08 de maio de 2001. Fala das diretrizes curriculares nacionais para a formação de professores para a educação básica, em nível superior, curso de licenciatura, de graduação plena. Distrito Federal, 2001.

BRASIL. Ministério da Educação. Conselho Nacional de Educação/ Conselho Pleno.

Resolução no. 01 de 18 de fevereiro de 2002. Institui diretrizes curriculares nacionais para a formação de professores da educação básica, em nível superior, curso de licenciatura, de graduação plena. Disponível em:

$<$ http://portal.mec.gov.br/seesp/arquivos/pdf/res1 2.pdf>. Acesso em: 09 jun. 2011.

BRASIL. Ministério da Educação. Conselho Nacional de Educação/Câmara de Educação Superior. Resolução no 7, de 31 de março 2004. Institui as diretrizes curriculares nacionais para os cursos de Educação Física, em nível superior de graduação plena. Disponível em:
$<$ http://www.udesc.br/arquivos/id submenu/83/res olucao 20047 cne ces.pdf>. Acesso em: 09 jun. 2011.

FUZII, F. T.; SOUZA NETO, S.; BENITES, L. C. Teoria da formação e avaliação no currículo de educação física. Motriz. Revista de Educação Física. UNESP, Rio Claro, v. 15, n. 1, p. 13-24, jan./mar. 2009.

GINZBURG, C. Mitos, embalagens, sinais: morfologia e história. São Paulo: Companhia das Letras, 1989.

GOODSON, I. F. As políticas de currículo e de escolarização: abordagens históricas. Petrópolis: Vozes, 2008.

MOREIRA, A. F. B.. Currículos e programas no Brasil. São Paulo: Papirus, 1995.

SACRISTÁN, J. G. Poderes instáveis em educação. Porto Alegre: ARTMED, 1999.

SACRISTÁN, J. G; GOMEZ, A. I. P. Compreender e transformar o ensino. Porto Alegre: ARTMED, 1998.

SANTOS, W. dos. Programa Escola de Gestores: um olhar sobre as práticas curriculares e avaliativas. In: SCHWARTZ, C. M.; ARAÚJO, G. C. de; RODRIGUES, P. da S. (org.). Escola de gestores da educação básica: reflexões e experiências do Programa Nacional Escola de Gestores da Educação Básica no Estado do Espírito Santo. 2 ed. Vitória: GM, 2010, p. 25-40.

SCHÖN, D. A. Educando o profissional reflexivo: o novo design para o ensino e a aprendizagem. Porto Alegre: ARTMED, 2000.

SILVA, T. T. da. Documentos de identidade: uma introdução ás teorias do currículo. Belo Horizonte: Autêntica, 2000.

Artigo derivado de tese de doutorado.

\section{Endereço:}

Marcello Pereira Nunes

Universidade Federal do Espírito Santo/UFES/ES

Av. São Paulo, 2514/101 Praia de Itapoã

Vila Velha ES Brasil

29101-502

Telefone: (27) 3349.7526 / (27) 9989.3736

e-mail: marcellonunes1@gmail.com 
Recebido em: 20 de setembro de 2011.

Aceito em: 13 de dezembro de 2011.

\section{(c) (7)}

Motriz. Revista de Educação Física. UNESP, Rio Claro,

SP, Brasil - elSSN: 1980-6574 - está licenciada sob

Creative Commons - Atribuição 3.0 